\title{
Reducing Climatology Bias in an Ocean-Atmosphere CGCM with Improved Coupling Physics
}

\author{
Jing-Jia LuO AND SEbAstien MASSON \\ Frontier Research Center for Global Change, JAMSTEC, Yokohama, Japan \\ ERICH ROECKNER \\ Max Planck Institute for Meteorology, Hamburg, Germany \\ GURVAN MADEC \\ Laboratoire d'Océanographie Dynamique et Climatologie, Paris, France \\ TOSHIO YAMAGATA* \\ Department of Earth and Planetary Science, The University of Tokyo, Tokyo, Japan
}

(Manuscript received 12 August 2004, in final form 15 November 2004)

\begin{abstract}
The cold tongue in the tropical Pacific extends too far west in most current ocean-atmosphere coupled GCMs (CGCMs). This bias also exists in the relatively high-resolution SINTEX-F CGCM despite its remarkable performance of simulating ENSO variations. In terms of the importance of air-sea interactions to the climatology formation in the tropical Pacific, several sensitivity experiments with improved coupling physics have been performed in order to reduce the cold-tongue bias in CGCMs.

By allowing for momentum transfer of the ocean surface current to the atmosphere [full coupled simulation (FCPL)] or merely reducing the wind stress by taking the surface current into account in the bulk formula [semicoupled simulation (semi-CPL)], the warm-pool/cold-tongue structure in the equatorial Pacific is simulated better than that of the control simulation (CTL) in which the movement of the ocean surface is ignored for wind stress calculation. The reduced surface zonal current and vertical entrainment owing to the reduced easterly wind stress tend to produce a warmer sea surface temperature (SST) in the western equatorial Pacific. Consequently, the dry bias there is much reduced. The warming tendency of the SST in the eastern Pacific, however, is largely suppressed by isopycnal diffusion and meridional advection of colder SST from south of the equator due to enhanced coastal upwelling near Peru. The ENSO signal in the western Pacific and its global teleconnection in the North Pacific are simulated more realistically.

The approach as adopted in the FCPL run is able to generate a correct zonal SST slope and efficiently reduce the cold-tongue bias in the equatorial Pacific. The surface easterly wind itself in the FCPL run is weakened, reducing the easterly wind stress further. This is related with a weakened zonal Walker cell in the atmospheric boundary layer over the eastern Pacific and a new global angular momentum balance of the atmosphere associated with reduced westerly wind stress over the southern oceans.
\end{abstract}

* Additional affiliation: Frontier Research Center for Global Change, JAMSTEC, Yokohama, Japan.

Corresponding author address: Jing-Jia Luo, Climate Variations Research Program, Frontier Research Center for Global Change, JAMSTEC, 3173-25 Showa-machi, Kanazawa-ku, Yokohama, Kanagawa 236-0001, Japan.

E-mail: luo@jamstec.go.jp

(C) 2005 American Meteorological Society 


\section{Introduction}

It has been reported in the last decade that state-ofthe-art ocean-atmosphere coupled general circulation models (CGCMs) have difficulties in correctly simulating the climatology and El Niño-Southern Oscillation (ENSO) variability in the tropical Pacific (e.g., Neelin et al. 1992; Mechoso et al. 1995; Latif et al. 1993; Delecluse et al. 1998; Latif et al. 2001; Davey et al. 2002; AchutaRao and Sperber 2002). Simply because both the climatology and interannual ENSO variability are substantially determined by air-sea interactions in the tropical Pacific (e.g., Bjerknes 1969; Dijkstra and Neelin 1995), any minor error in an uncoupled model could be amplified through unstable interactions and lead to erroneous behaviors in CGCMs. Concerning the tropical Pacific climatology biases, most current coupled models fail to produce the large annual cycle of sea surface temperature (SST) in the eastern Pacific, the interhemispheric asymmetry of the intertropical convergence zone (ITCZ), and the sharp warm-pool/coldtongue structure. Although model biases of ENSO simulation vary with different CGCMs, it has been stated that most of them produce more frequent ENSO events with poor phase locking to the seasonal cycle (AchutaRao and Sperber 2002). The ENSO teleconnection in the extratropics is weak and not simulated properly (Davey et al. 2002). Currently, there is no direct evidence that the model climatology biases could lead to the biases of simulated ENSO variations (Latif et al. 1993; AchutaRao and Sperber 2002).

As part of a European Union (EU)-Japan collaboration, we have developed a relatively high-resolution coupled GCM at the Frontier Research Center for Global Change (FRCGC), named the Scale Interaction Experiment-FRCGC (SINTEX-F) model (Luo et al. 2003). This model produces realistic ENSO magnitudes, the meridional broadness of SST anomalies, and the ENSO period of 3-5 yr (Gualdi et al. 2003; Luo et al. 2003). The phase locking of ENSO with the seasonal cycle is also captured reasonably well (Tozuka et al. 2005). Such a remarkable performance of the ENSO simulation is found to be related to the high resolution (T106) of the atmosphere GCM (Guilyardi et al. 2004). However, the three common climatology biases in the tropical Pacific that are described above still exist in the SINTEX-F CGCM. The model produces a very weak annual cycle of the Niño-3 SST, $\left(5^{\circ} \mathrm{N}-5^{\circ} \mathrm{S}, 90^{\circ}-150^{\circ} \mathrm{W}\right)$ but with a pronounced semiannual signal (see Fig. $4 \mathrm{c}$ in section 3). The warm-pool SST in the western South Pacific stretches zonally to the east to $\sim 120^{\circ} \mathrm{W}$, and the equatorial cold tongue of SST extends too far west (Fig. 1a). The SST errors tend to cause a double-ITCZ bias,
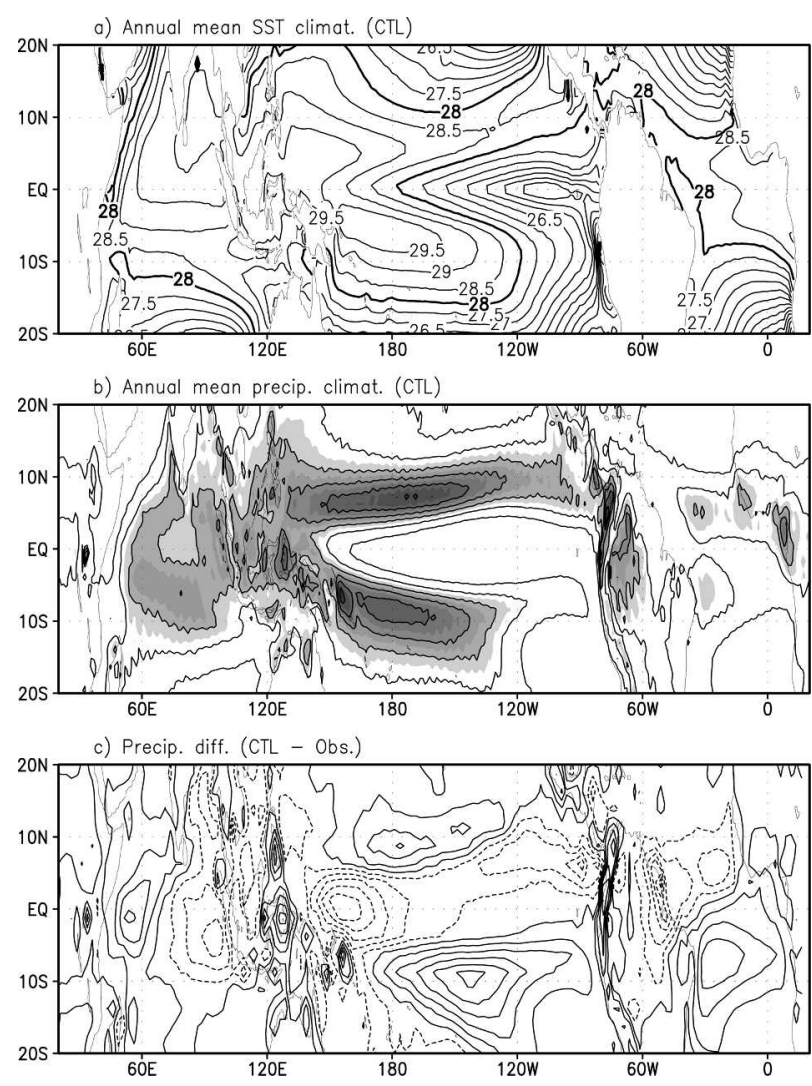

FIG. 1. Annual mean climatologies of (a) SST and (b) precipitation (contour: $2 \mathrm{~mm} \mathrm{day}^{-1}$ ) based on the CTL run from model years 21 to 120 . Regions with values larger than $5 \mathrm{~mm} \mathrm{day}^{-1}$ are shaded. (c) Differences between the model climatological precipitation and Xie and Arkin's (1996) observations averaged for the period of 1979-2002 (contour: $1 \mathrm{~mm} \mathrm{day}^{-1}$ ).

with a maximum value of about $5 \mathrm{~mm} \mathrm{day}^{-1}$ in the South Pacific and a dry bias of $-5 \mathrm{~mm} \mathrm{day}^{-1}$ in the western equatorial region, compared to the Xie and Arkin (1996) analysis (Figs. 1b and 1c). The doubleITCZ bias is primarily a result of excessive precipitation south of the equator during the boreal winter and spring seasons. The dry bias in the western Pacific, however, persists for all four seasons. Near the coast of Peru, the model SST is too high, with a maximum value that is $\sim 3^{\circ} \mathrm{C}$ warmer than that of the observed 1950-99 Hadley Centre Global Sea Ice Coverage and Sea Surface Temperature Data (HadISST1.1) climatology (Rayner et al. 2003). This may be related to the AGCM deficiency in low-level stratus cloud simulation (not shown) and weaker southeast (SE) trade winds in the coastal region (see Fig. 2b). Such AGCM biases are thought to be origins of the double-ITCZ bias, which might lead to a weak annual SST cycle in the eastern Pacific (Mechoso et al. 1995; Ma et al. 1996; Latif et al. 2001).

Several theoretical studies have suggested that the 
a) Tau diff. (CTL - ERS)

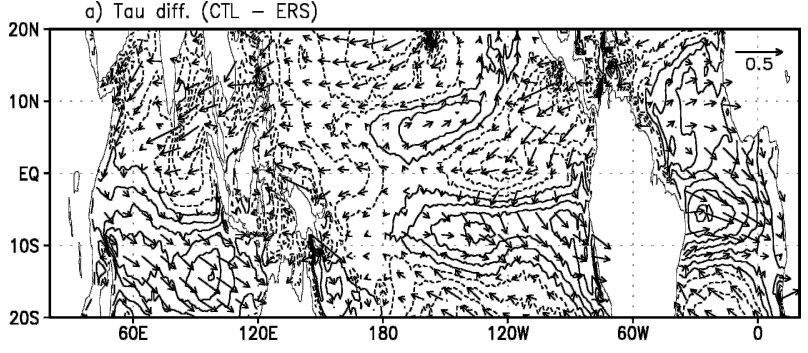

b) Tau diff. (AGCM - ERS)

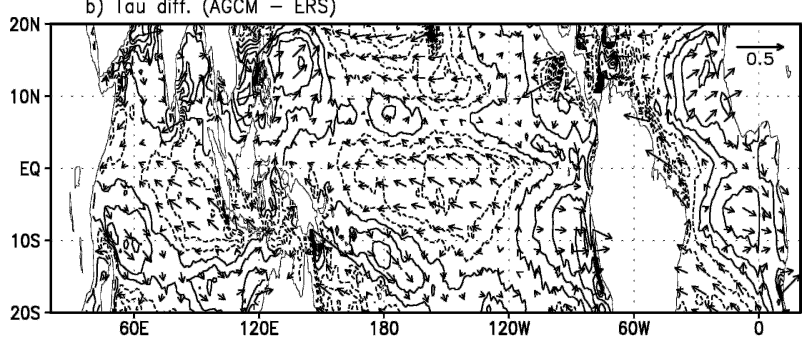

c) U $5 \mathrm{~m}$ climat. (CTL)

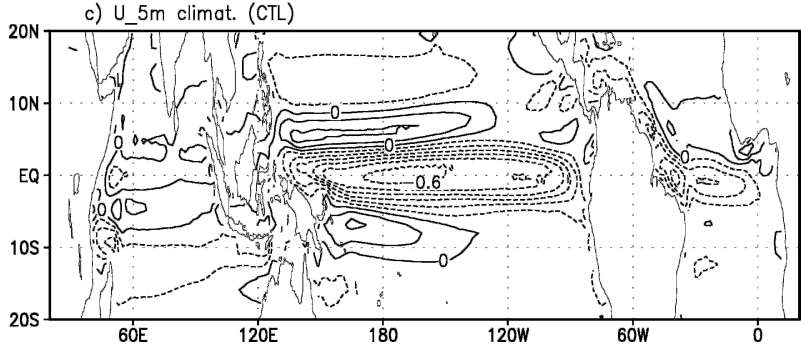

FIG. 2. (a) Same as in Fig. 1c, but for the surface wind stress differences between the model climatology and the ERS observations averaged from Mar 1992 to Dec 2000. Contours denote the differences of zonal wind stress (contour: 0.05 dyne $\mathrm{cm}^{-2}$ ). (b) Same as (a), but for differences of the uncoupled AGCM outputs from Mar 1992 to Dec 2000 forced by HadISST observations. (c) Same as in Fig. 1a, but for the zonal ocean surface current at 5-m depth (contour: $0.1 \mathrm{~m} \mathrm{~s}^{-1}$ ).

tropical Pacific warm-pool/cold-tongue configuration, as much as the interannual ENSO variability, could also be the result of air-sea interactions in which surface wind stress acts as a key measure of the coupling strength associated with the Walker and Hadley circulations (Dijkstra and Neelin 1995; Liu and Huang 1997; Jin 1998). Some coupled model experiments have shown that strong easterly wind stress in the equatorial Pacific tends to push the cold tongue too far to the west (Meehl et al. 2001; Schneider 2002). As shown in Fig. 2a, this is also true in the SINTEX-F model. Compared to the European Space Agency (ESA) Remote Sensing Satellite (ERS) observations, the model easterly wind stress is too strong in the entire equatorial Pacific except the central region. It forces a strong westward surface current that intrudes far into the western boundary (Fig. 2c). The westward current reaches above $0.6 \mathrm{~m} \mathrm{~s}^{-1}$ in the central equatorial Pacific. As found by Davey et al. (2002), most CGCMs produce an easterly wind stress in the western Pacific, which is too strong; this is probably related to the dry bias there. The strong easterly wind stress in the equatorial Pacific can be traced back to the bias of the atmosphere GCM forced by observed SST (Fig. 2b). The AGCM produces SE trade winds that are too strong in most parts of the equatorial Pacific. Following a classical approach, one may tune the AGCM to get better wind fields. However, one needs to consider the oceanic feedback even when tuning uncoupled AGCMs because the ocean surface is moving rather than resting (the current assumption of AGCMs). An early study of Pacanowski (1987), using an OGCM for the tropical Atlantic, showed that the equatorial easterly wind stress could be reduced by $\sim 30 \%$ if the ocean surface current is taken into account. This leads to $\sim 1^{\circ} \mathrm{C}$ warming in SST. Recent satellite observations also suggested the importance of ocean surface velocities in computing the wind stress over regions with strong currents (Kelly et al. 2001; Chelton et al. 2004). Furthermore, the excessive westward extension of the equatorial Pacific cold tongue is a common bias appearing in most current CGCMs in which the atmosphere components have various different wind biases. This requires a common approach to working with CGCMs. Zonal oceanic surface velocity is strong in the equatorial Pacific (as much as $\sim 15 \%$ of the surface wind velocity). It may have important effects on the generation of the warm-pool/cold-tongue structure in terms of the air-sea positive feedbacks.

In this study, we focus on one of the model common biases: the cold tongue extends too far west in the equatorial Pacific. In other words, the model zonal SST gradient along the equator is weaker than the observations. Using the SINTEX-F coupled model, we have performed several sensitivity experiments in order to reduce this bias. By taking the ocean surface current into account for wind stress calculation, all experiments produce better warm-pool/cold-tongue structures in the equatorial Pacific. The coupled model and sensitivity experiments are described in section 2. Experimental results are presented in section 3, and possible reasons for differences among the experimental results are discussed in section 4. A summary and discussion is given in section 5 .

\section{The coupled GCM and the sensitivity experiments}

The SINTEX-F coupled model has been developed from the original European SINTEX model (Gualdi et al. 2003; Guilyardi et al. 2003). The ocean component is the reference version 8.2 of Océan Parallélisé (OPA; Madec et al. 1998) with the ORCA 2 configuration: an 
Arakawa-C type grid based on a $2^{\circ}$ Mercator mesh. In the Northern Hemisphere, the mesh has two poles and the anisotropy ratio is nearly one everywhere. As a result, the singularity at the North Pole disappears. The model resolution is $2^{\circ} \cos \left(\right.$ latitude) $\times 2^{\circ}$ (longitude) with increased meridional resolutions to $0.5^{\circ}$ near the equator. It has 31 vertical $z$ levels of which 19 lie in the top $400 \mathrm{~m}$. We adopted the same model physics as were used in OPA version 8.1 (OPA8.1), the ocean component of the original SINTEX model (Guilyardi et al. 2003), except that a free surface configuration (Roullet and Madec 2000) and Gent and McWilliams (1990) scheme for isopycnal mixing have been included. Vertical eddy diffusivity and viscosity coefficients are calculated from a 1.5-order turbulent closure scheme (Blanke and Delecluse 1993). Compared with the previous version, OPA8.2 has adopted better river runoff climatologies. Closed seas have been added with slight modifications of the coastline.

The atmosphere component is the latest version of ECHAM4 in which the Message Passing Interface is applied to a parallel computation (Roeckner et al. 1996). We adopted a high horizontal resolution (T106) of about $1.1^{\circ} \times 1.1^{\circ}$. A hybrid sigma-pressure vertical coordinate (19 levels in all) is used with the highest resolution near the earth's surface. The prognostic variables include vorticity, divergence, temperature, surface pressure, water vapor, and cloud water. Momentum is calculated from the vorticity and divergence fields with additional contributions from surface friction, gravity wave drag, and cumulus friction. Model physical processes are the same as those of ECHAM4.0, the atmosphere component of the original SINTEX model (Gualdi et al. 2003), including the Tiedtke (1989) bulk mass flux formula for cumulus convection and the Morcrette et al. (1986) radiation code. The surface turbulent flux is calculated according to a bulk aerodynamic formula in which the drag coefficients for momentum and heat are estimated based on an approximate analytical function of the moist bulk Richardson number and roughness length (Louis 1979). Over the open water, the aerodynamic momentum roughness length is estimated from friction velocity (Charnock 1955). We note that, over the real ocean, both the magnitude and direction of surface wind stress could be affected by the sea state (e.g., surface waves and their ages). A proper surface wave model that is coupled to atmosphere-ocean GCMs (AOGCMs) would improve the wind stress calculation physically.

The coupling fields are exchanged every $2 \mathrm{~h}$ between the ocean and atmosphere by means of the Ocean Atmosphere Sea Ice Soil (OASIS) 2.4 coupler (Valcke et al. 2000). Surface wind stress, water, and heat flux from the atmosphere (SST, sea ice cover, and surface current from the ocean) are interpolated to the oceanic (atmospheric) grid based on an area-weighted scheme. Global conservations of the interpolated fields are maintained to the first order. The coupled model does not apply any flux correction, except that sea ice cover is relaxed toward observed monthly climatologies in the OGCM. The initial condition of the atmosphere is provided by a 1-yr run forced with observed monthly climatological SSTs. The ocean is started from the Levitus annual mean climatologies with zero velocities.

To examine effects of the ocean surface current on the tropical Pacific warm-pool/cold-tongue structure in a coupled GCM, we have designed several sensitivity experiments. In addition to the control run (CTL), in which effects of the ocean surface current on wind stress are ignored as they are in most existing CGCMs, we designed another experiment in which the surface current momentum was directly passed to the atmosphere through the vertical diffusion term in its momentum equation [the full coupled simulation (FCPL)]. This affects not only the surface wind stress and heat flux. It also affects the global angular momentum budget of the atmosphere as will be shown in section 4 . In the third experiment [the semicoupled simulation (semi-CPL)], the ocean surface was kept solid relative to the atmosphere, but the surface wind stress (only) was calculated by taking the ocean surface current into account, as was done in the FCPL run. That is, $\tau=$ $\rho_{a} C_{D}\left|\mathbf{v}_{a}-\mathbf{v}_{o}\right|\left(\mathbf{v}_{a}-\mathbf{v}_{o}\right)$. Here, $\rho_{a}$ is the density of air, $C_{D}$ is the drag coefficient, $\mathbf{v}_{a}$ is the wind velocity at the lowest level of the AGCM, and $\mathbf{v}_{o}$ is the ocean surface velocity at a 5-m depth (the uppermost layer of the OGCM). The semi-CPL approach is similar to the work of Pacanowski (1987) except that we apply it to a fully coupled GCM. In this case, the surface heat flux is indirectly affected by the surface current through changing SST. We note that the surface momentum exchanges between the atmosphere and ocean are inconsistent with each other in the semi-CPL experiment. Such an approach, however, could serve as a practical method, which will provide an idea about effects of the ocean surface current. All three experiments have been run for 120 yr starting from the same initial conditions. We note that, even in the Tropics, such long-term integrations are necessary to obtain robust climatologies. This has been suggested by some sensitivity experiment results in which the atmospheric noise forcing is slightly randomly modified (not shown). Neglecting the 20-yr spin-up period, the last $100 \mathrm{yr}$ of the FCPL and semi- 
CPL runs are compared to those of the CTL run in the following two sections.

\section{Results}

\section{a. Climatology differences}

Figure 3a shows the 100-yr mean tropical SST differences between the FCPL and CTL run. Much warmer SST appears in the western equatorial Pacific with a maximum value of $\sim 0.8^{\circ} \mathrm{C}$. Near the equatorial eastern boundary the SST is also greater, but with a smaller value of about $0.4^{\circ} \mathrm{C}$. In contrast, colder SST appears near the coast of Peru and extends northwestward to the equator as far as $\sim 120^{\circ} \mathrm{W}$. This is a result of the stronger surface southerlies in the coastal region and enhanced coastal upwelling (Ma et al. 1996). A similar pattern of SST differences also appears in the Atlantic, but with much weaker values along the equator. The semi-CPL run also produces warmer SSTs in the western Pacific and colder SSTs extending northwestward from the coast of Peru (Fig. 3b). The spatial pattern of the SST differences is similar to that of the FCPL run, but with weaker magnitudes. The SST increase in the western equatorial Pacific is only $0.3^{\circ}-0.4^{\circ} \mathrm{C}$, about half of that of the FCPL run. Figure $3 \mathrm{c}$ shows the annual mean SST climatologies along the equator from the observations and three experiments. The zonal SST gradient of the CTL run in the equatorial Pacific (Fig. $3 \mathrm{c}$, dot-dot-dashed line) is much weaker than the observations (Fig. 3c, solid line); a warmer (colder) SST, relative to the observations, appears in the eastern (western) Pacific. By including effects of the ocean surface current in the semi-CPL and FCPL runs, the warmpool/cold-tongue configuration in the equatorial Pacific has been better simulated (Fig. 3c, long- and shortdashed lines). In particular, the zonal SST slope of the FCPL run is almost the same as that of the observations. This suggests that the correct coupling physics is important to produce the correct warm-pool/coldtongue structure in the tropical Pacific (e.g., Dijkstra and Neelin 1995). Because the SST in the eastern Pacific plays an important role in the air-sea interactions, a model bias there could trigger a similar bias basinwide (see Luo et al. 2005). Keeping the coupling physics of the FCPL run and reducing the warm bias in the eastern Pacific, owing to the underestimated low-level stratus cloud and weaker SE trade winds there, we would expect to obtain not only the correct zonal SST gradient but also the correct SST values in the equatorial Pacific. In the Indian Ocean and near the maritime continents, the zonal SST gradient along the equator is simulated realistically by all three of the experiments (Fig. 3c), but their mean states are too warm compared to the obser-
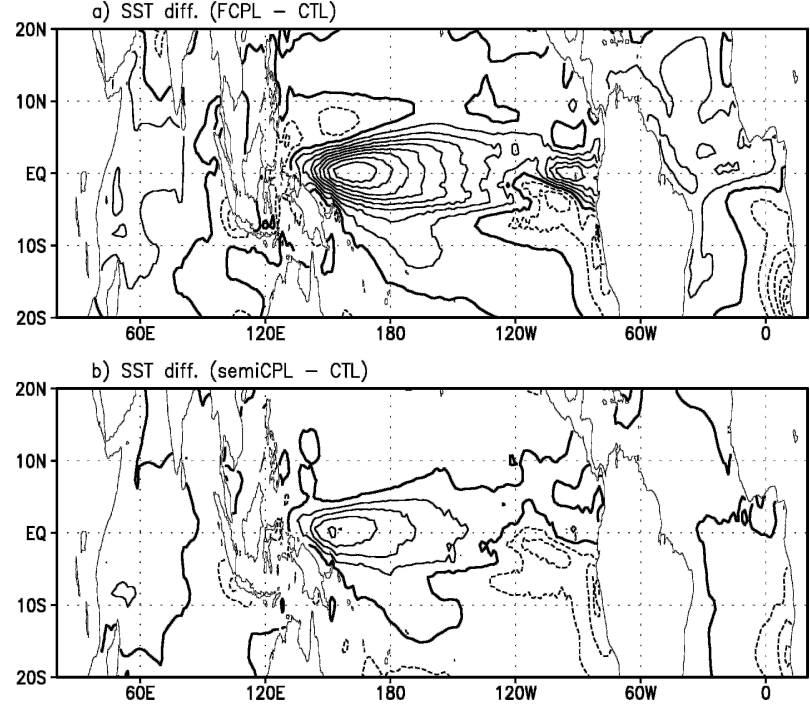

c) SST climat. $(2 \mathrm{~S}-2 \mathrm{~N})$

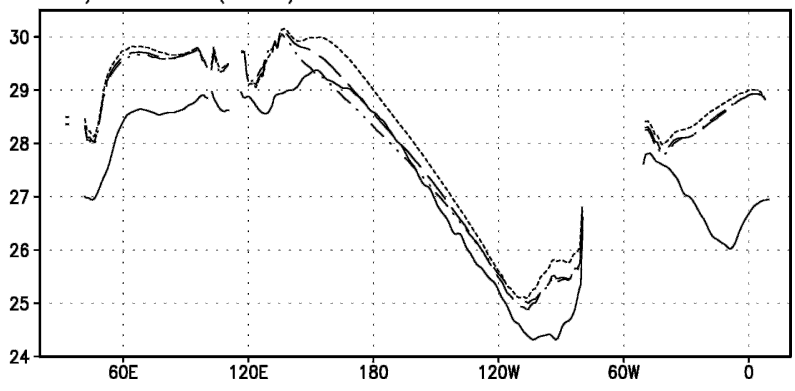

FIG. 3. The last 100-yr mean SST differences between (a) the FCPL and CTL, and (b) the semi-CPL and CTL runs. Contour interval is $0.1^{\circ} \mathrm{C}$. Thick solid lines denote zero contours. (c) Annual mean SST climatology along the equator $\left(2^{\circ} \mathrm{S}-2^{\circ} \mathrm{N}\right)$ from the HadISST observations averaged for the period of 1950-99 (solid line), the CTL (dot-dot-dashed line), semi-CPL (long-dashed line), and FCPL (short-dashed line) runs.

vations. In the Atlantic, however, the model produces opposite zonal SST gradients. This is probably because of underestimated low-level stratus cloud and weaker SE trade winds in the western South Atlantic (Fig. 2b, see also Davey et al. 2002).

It is also interesting to check the effects of the ocean surface current on the mean seasonal cycle of equatorial SST. In the eastern Pacific, a large seasonal SST migration exists because of the slant of the American continents and air-sea interactions (e.g., Mitchell and Wallace 1992; Xie and Philander 1994; Philander et al. 1996). The signal of the annual SST cycle propagates further westward along the equatorial Pacific as a result of the positive feedback between the SST, wind stress, and oceanic upwelling (e.g., Horel 1982; Chang and Philander 1994). By adding the ocean surface current directly into the air-sea coupled system, a warmer SST 
appears in the western equatorial Pacific through all of the seasons in the FCPL and semi-CPL runs (Figs. 4a and 4b). SST in the eastern Pacific, however, becomes warmer than that of the CTL run primarily during the spring, with much warming located near the eastern boundary. The warming magnitude of the FCPL run $\left(0.9^{\circ} \mathrm{C}\right)$ is much larger than that of the semi-CPL run $\left(0.4^{\circ} \mathrm{C}\right)$. Unlike the SST warming in the west, the spring warming in the eastern Pacific induces stronger southeast trade winds and, hence, strengthens the coastal upwelling south of the equator. This leads to much colder SSTs intruding northwestward from the coastal region into the equator in the following summer. The effect of the colder SST in the eastern Pacific may extend westward along the equator as far as the date line (Figs. 4a and 4b). We note that, in the semi-CPL experiment, the colder SST near the eastern boundary of Pacific even persists until early in the following winter (Fig. 4b). Similar behavior can also be seen in the equatorial Indian Ocean and the Atlantic. The spring warming in the eastern Pacific leads to a slightly better annual cycle of the Niño-3 SST. In particular, the spring peak in the FCPL and semi-CPL runs is closer to that of the observations (Fig. 4c). Associated with the doubleITCZ bias, however, the pronounced semiannual signal in the Niño-3 region still exists.

To examine reasons for the persistent warmer SSTs in the western equatorial Pacific that are produced by the semi-CPL and FCPL runs, we plot in Fig. 5 differences with the CTL run of the ocean zonal surface velocity at a 5-m depth and of the wind stress. Clearly, the warmer SST in the western Pacific is closely related with the reduced climatological westward surface current throughout the equatorial Pacific (Figs. 5a and 5c); a weaker westward current would lead to weaker advection of cold SSTs from the east. This is consistent with the study of Picaut et al. (1996) who showed that the zonal surface current has important effects on the east-west migrations of the warm pool that are associated with the ENSO events. The weaker surface current is caused by reduced easterly wind stress. The latter is now calculated based on the relative velocity between the surface wind and ocean current (Figs. 5b and 5d). Interestingly, reductions of the surface westward current and easterly wind stress in the FCPL run are double those in the semi-CPL run. This may partly explain why the SST warming in the western equatorial Pacific is twice that of the semi-CPL run (see Figs. 3a and $3 \mathrm{~b}$ ). Another important factor is that the vertical entrainment of subsurface cold water into the mixed layer is weakened as a result of the reduced easterly wind stress. This tends to generate warmer SST in the
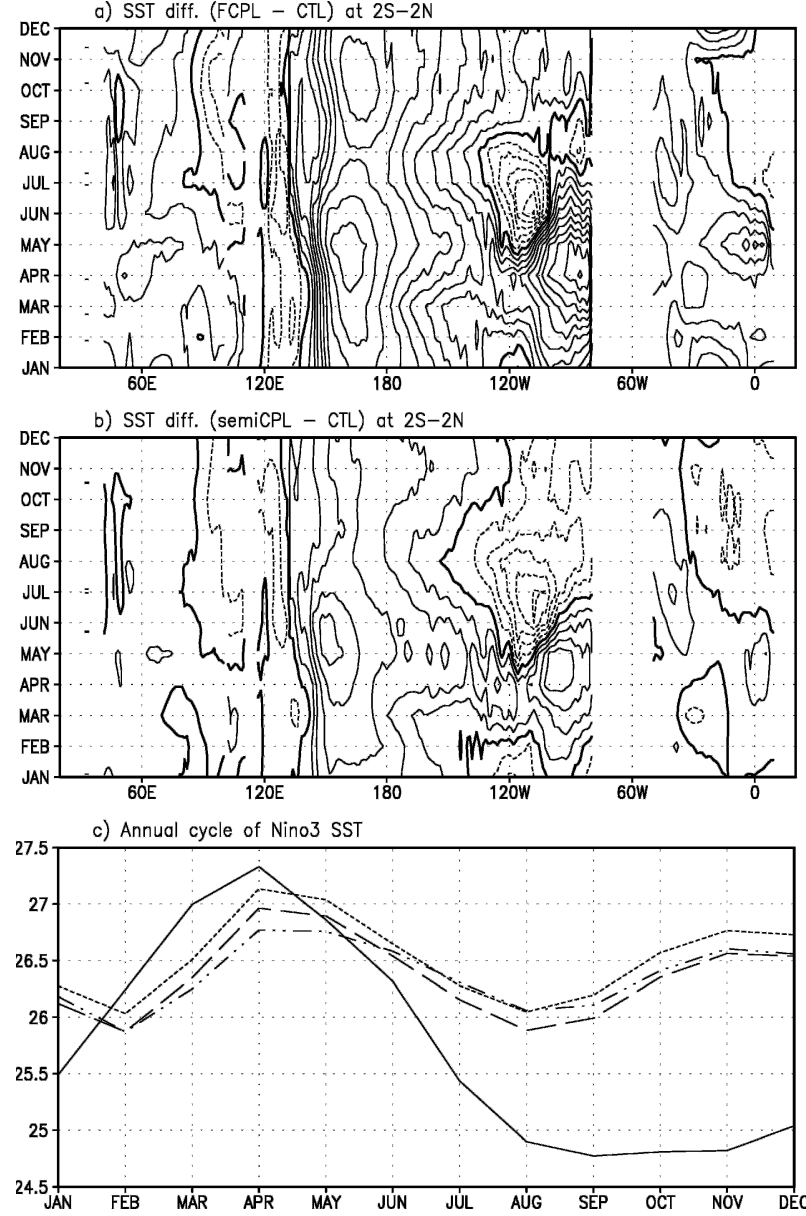

FIG. 4. (a), (b) Same as Figs. 3a and 3b, but for differences of the mean seasonal cycle of SST along the equator $\left(2^{\circ} \mathrm{S}-2^{\circ} \mathrm{N}\right)$. (c) Same as Fig. 3c, but for the annual mean cycle of Niño-3 SST $\left(5^{\circ} \mathrm{N}-5^{\circ} \mathrm{S}, 90^{\circ}-150^{\circ} \mathrm{W}\right)$.

entire equatorial Pacific. Further discussions on this issue are given in section 4.

Associated with the warmer SST in the western equatorial Pacific, large-scale convergence of surface air from south and north of the equator appears in the western Pacific (Figs. 5b and 5d). This leads to more convective precipitation and fresher surface water in this region (Fig. 6). The dry bias in the western equatorial Pacific has now been reduced, and the oceanic barrier layer therein is simulated better. Consistent with the SST differences there, improvements of precipitation and sea surface salinity in the FCPL run are also much larger than those in the semi-CPL run. In the western Pacific, $3 \mathrm{~mm}$ day ${ }^{-1}$ more precipitation is produced in the FCPL run; this reduces by about $60 \%$ the original dry bias in the CTL run (see Fig. 1c). In addition, the excessive precipitation bias in the South $\mathrm{Pa}$ cific is also slightly reduced because of an enhanced atmospheric Hadley cell (not shown). 
a) U_5m diff. (FCPL - CTL)

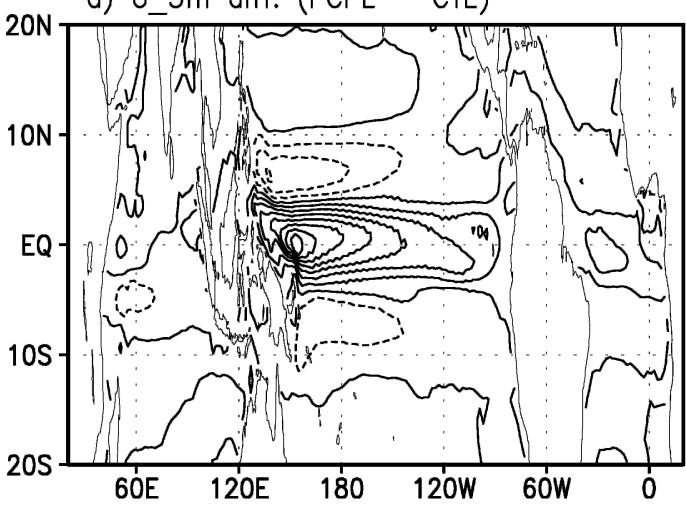

b) Tau diff. (FCPL - CTL)

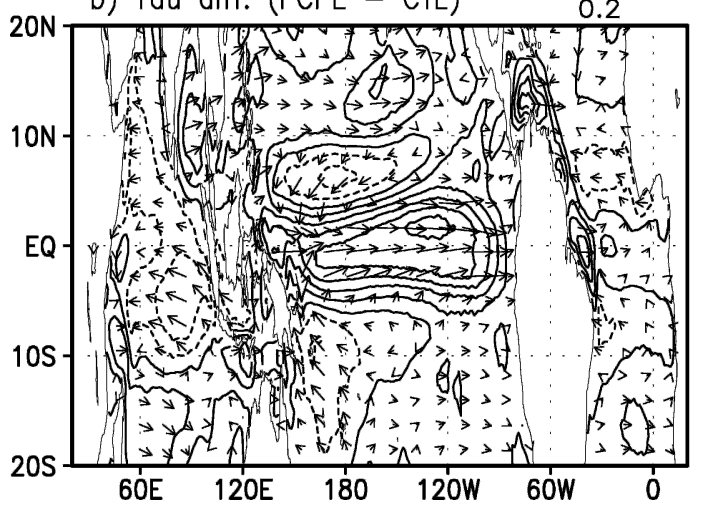

c) U_5m diff. (semiCPL - CTL)

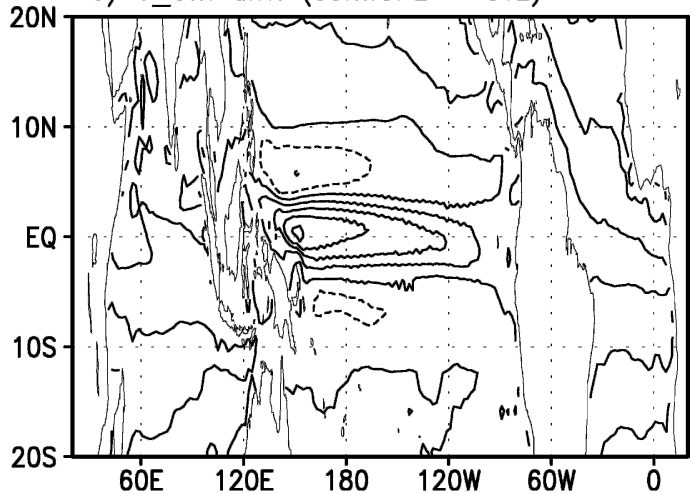

d) Tau diff. (semiCPL - CTL) $\quad \overrightarrow{0.2}$

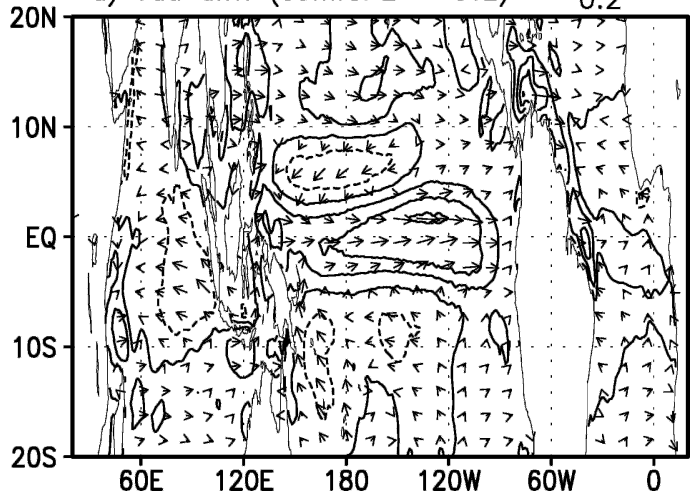

FIG. 5. Same as in Fig. 3a, but for differences of (a) the ocean surface current at 5-m depth (contour: $5 \mathrm{~cm} \mathrm{~s}^{-1}$ ) and (b) the surface wind stress between the FCPL and CTL runs. Contours in (b) denote differences of the zonal wind stress (contour: 0.02 dyne $\mathrm{cm}^{-2}$ ). (c), (d) Same as (a), (b), but for differences between the semi-CPL and CTL runs.

\section{b. ENSO simulation}

Figure 7 shows typical SST and surface wind anomalies related to ENSO variations based on the three experiment results and observations. In general, the ENSO signal and its global teleconnection pattern are simulated realistically by all three experiments. We note that the ENSO frequency does not change much; all three experiments produce a principal period of 3-5 yr. Compared to the CTL run and observations, ENSO amplitudes of the FCPL and semi-CPL runs are slightly smaller, especially in the region east of about $120^{\circ} \mathrm{W}$. This is not surprising because the variance of the zonal wind stress in the equatorial Pacific has been reduced when taking the ocean surface current into account (Figs. 8a and 8c). For instance, an easterly gust tends to induce a strong surface current in the same direction. Perturbations of the wind stress are, thus, smaller than those that do not include the contribution of the surface current. This reduces the oceanic thermocline variance (Figs. $8 \mathrm{~b}$ and $8 \mathrm{~d}$ ). East of about $120^{\circ} \mathrm{W}$, SST changes are closely coupled with thermocline fluctuations. This is consistent with the reduced ENSO SST magnitudes there. The east-west slopes of the equatorial Pacific thermocline are flattened because of the reduced climatological easterly wind stress (i.e., the thick dashed lines in Figs. 8b and 8d). The slopes are measured by the depth of the strongest vertical temperature gradient. In the western and central equatorial Pacific, however, the variance of the upper thermocline layer is increased because of the upraised mean thermocline. The flatter thermocline in the FCPL run, caused by the weaker mean easterly wind stress in the equatorial $\mathrm{Pa}$ cific, leads to larger differences in the thermocline variance compared with the semi-CPL run, despite the fact that reductions in wind stress variance there are almost the same (Figs. 8a and 8c).

Despite the slight weakening of ENSO amplitudes east of $\sim 120^{\circ} \mathrm{W}$ (they are still realistic with regard to the large decadal variability of ENSO; see Davey et al. 2002), some significant improvements can be seen in the FCPL and semi-CPL runs. In the CTL run, the ENSO signal in the equatorial Pacific extends too far west, across almost the whole basin (Fig. 7a). This is related to a similar bias of the cold tongue. By improving the coupling physics, the westernmost tip of the 
a) Precip. diff. (FCPL - CTL)

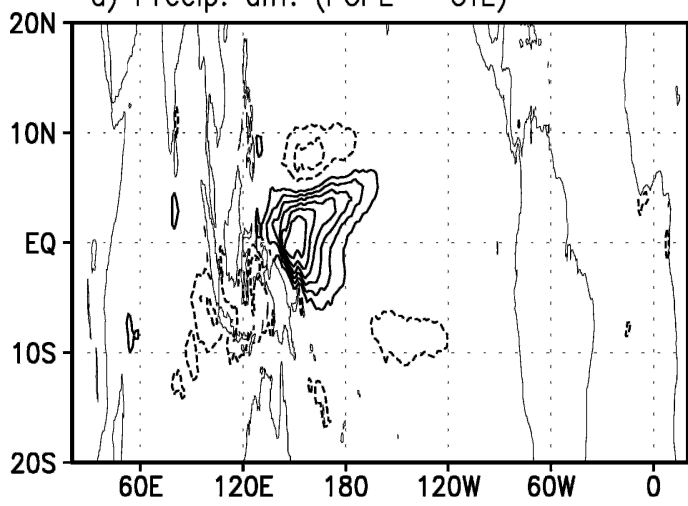

b) SSS diff. (FCPL - CTL)

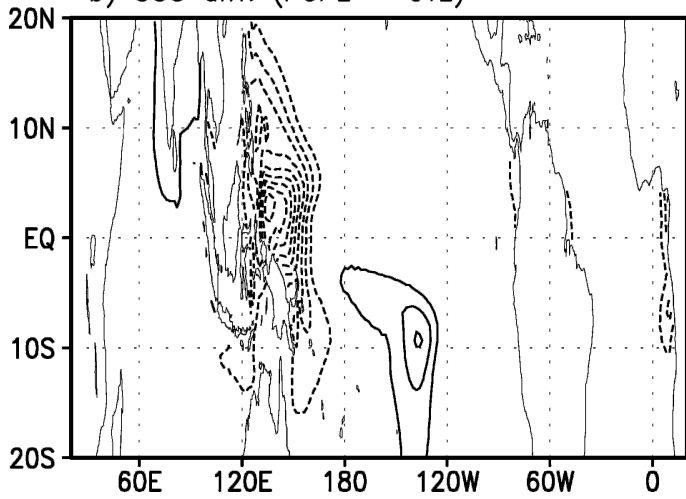

c) Precip. diff. (semiCPL - CTL)

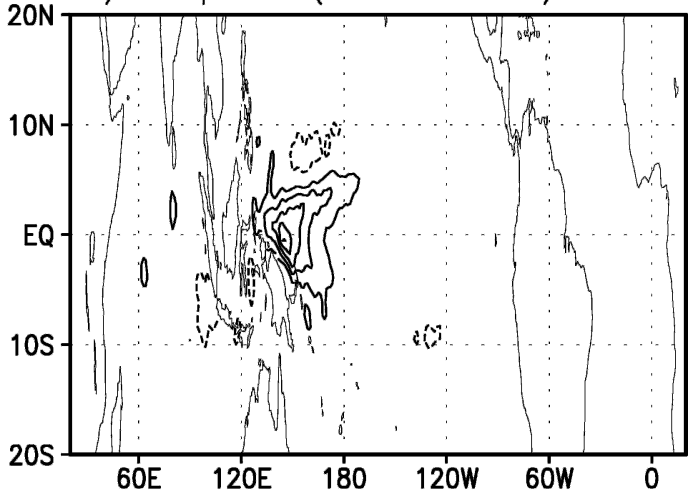

d) SSS diff. (semiCPL - CTL)

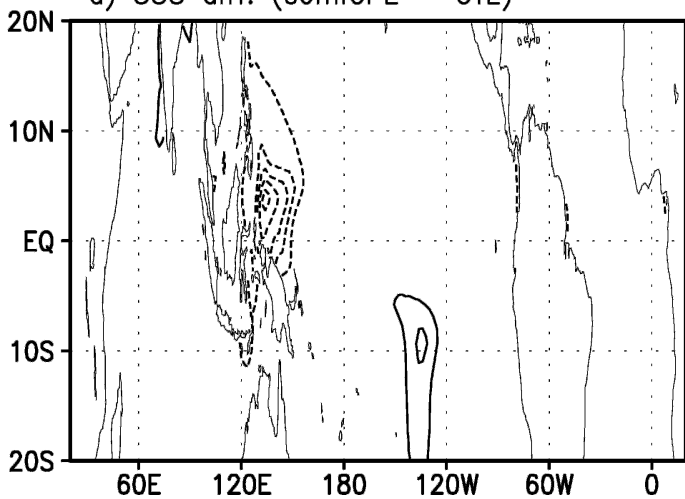

FIG. 6. Same as in Fig. 5, but for differences of precipitation (contour: $0.5 \mathrm{~mm} \mathrm{day}^{-1}$ ) and of sea surface salinity (SSS; contour: $0.2 \mathrm{psu}$ ). Zero contours have been removed for clarity.

ENSO signal retreats eastward, and weak cold SST anomalies now appear north of New Guinea Island in the semi-CPL run (Fig. 7b). With the correct warmpool/cold-tongue configuration in the FCPL run, the simulated ENSO signal is very close to the observations with significant cold SST anomalies appearing around New Guinea Island (Figs. 7c and 7d). Moreover, the ENSO teleconnection signal in the North Pacific has been improved. Associated with the El Niño events, the cold SST anomalies of the CTL run in the North Pacific are too weak and located too far south compared to the observations (Figs. 7a and 7d). With better simulations of the warm-pool SST and ENSO variability in the equatorial western Pacific, the shape and location of the cold SST anomalies in the central North Pacific are realistically captured in the semi-CPL and FCPL runs (Figs. $7 \mathrm{~b}$ and $7 \mathrm{c}$ ). The warm SST anomalies along the eastern boundary in the North Pacific are also simulated better compared with the CTL run. We note that the ENSO-induced signals in the Indian and Atlantic Oceans are similar to the observations; differences among the three experiments are negligible. The atmospheric teleconnection pattern in the Northern Hemisphere can be seen clearly from the geopotential height anomalies at a 500-hPa level during winter (Fig. 9). The anomalous cyclone center in the North Pacific associated with El Niño events is located near the date line in the CTL run (Fig. 9a). However, the location of the cyclone center, which has a larger amplitude, is shifted eastward in the semi-CPL and FCPL runs (Figs. 9b and 9c), closely approaching the observations (Fig. 9d). Improved simulation of the ENSO teleconnection pattern in the North Pacific can also be seen from the surface winds (see Fig. 7). Over the North American continent, amplitudes of the anticyclone anomaly are also simulated well in the semi-CPL and FCPL runs. However, the simulated anticyclone signals there are shifted northward and extended too far to the east.

\section{Understanding the differences among the three experiments}

a. Why is the surface wind stress reduced more in FCPL than in semi-CPL?

As shown in the previous section, the SST warming in the FCPL run in the western equatorial Pacific, relative to the SST climatology of the CTL run, is about twice that of the semi-CPL run. This is closely related to 


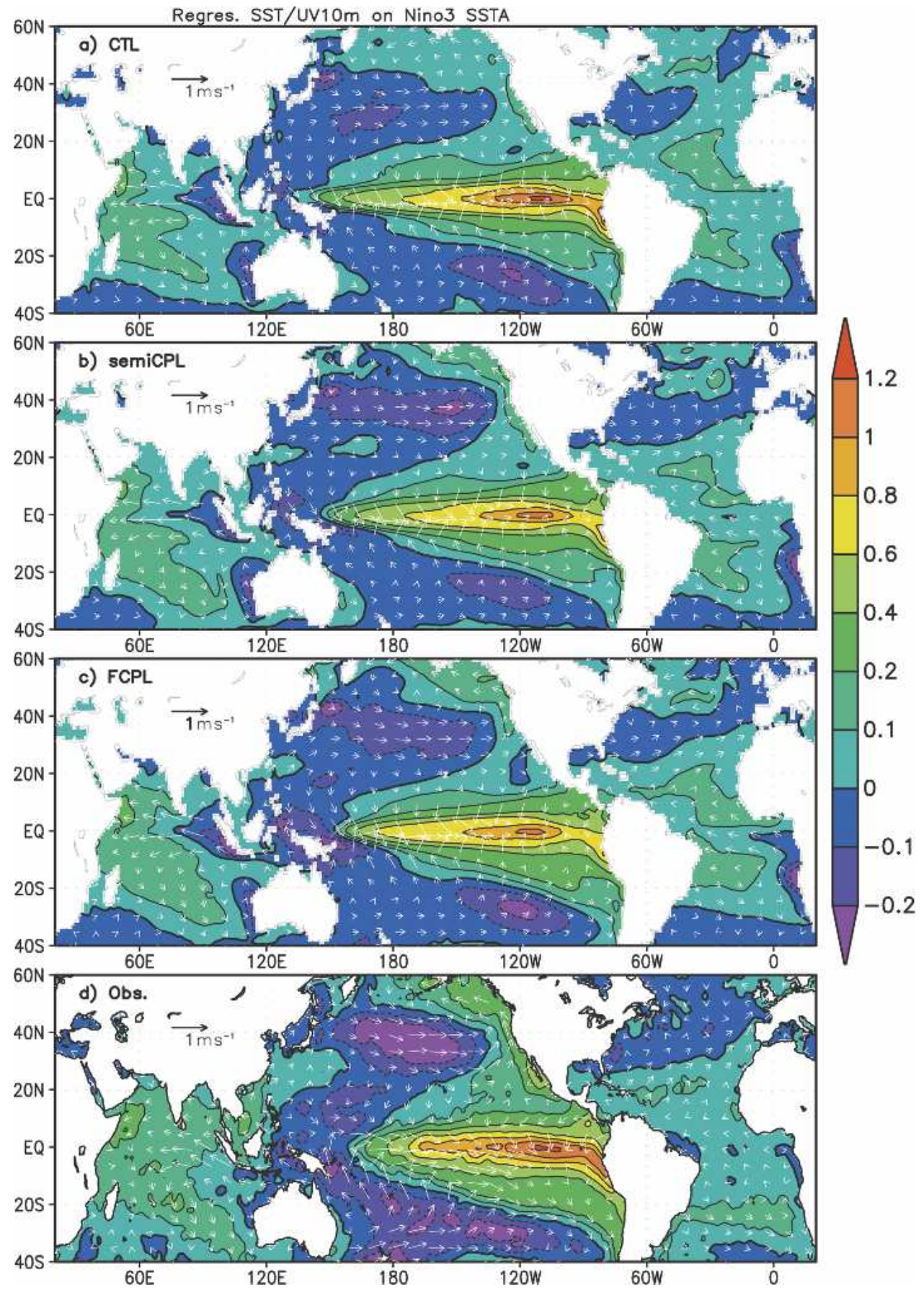

FIG. 7. Linearly regressed SST and surface winds anomalies on the Niño-3 SST index for the (a) CTL, (b) semi-CPL, and (c) FCPL runs, and (d) the observations [i.e., HadISST and National Centers for Environmental Prediction (NCEP) reanalysis data for the period 1950-99]. Thick solid lines denote zero contours.

the twofold reduction of the surface easterly wind stress in the equatorial Pacific. To understand this, we plot in Fig. 10 differences of the tropical winds at a 10-m height and 700-hPa level. In accordance with the classical Matsuno-Gill pattern (Matsuno 1966; Gill 1980), one can easily understand the wind differences between the semi-CPL and CTL runs. More westerlies (easterlies) appear west (east) of the warmer SST in the western equatorial Pacific (Figs. 10a and 10b). One might expect that the FCPL approach would generate much 
a) STD diff. of Taux (FCPL - CTL)

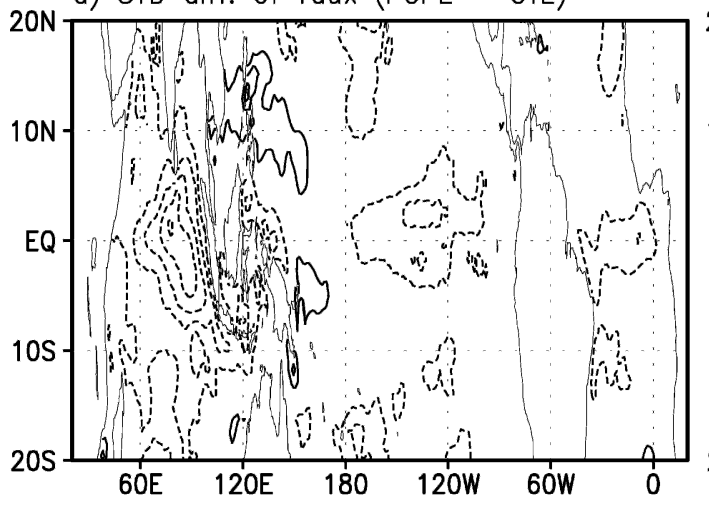

b) STD diff. of temp. at $4 \mathrm{~S}-4 \mathrm{~N}$

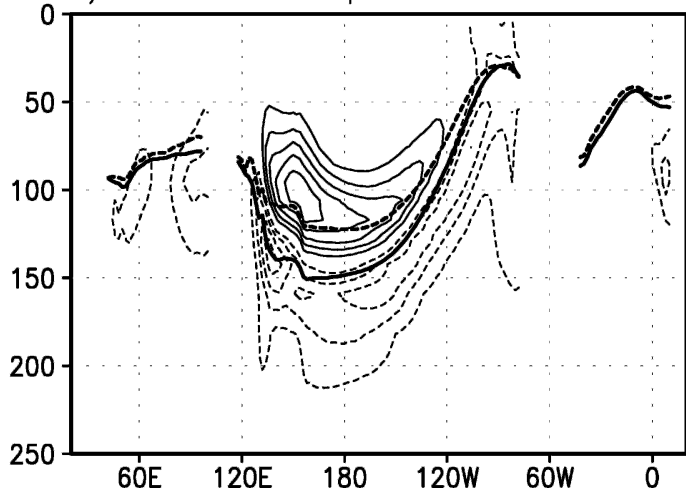

c) STD diff. of Taux (semiCPL - CTL)

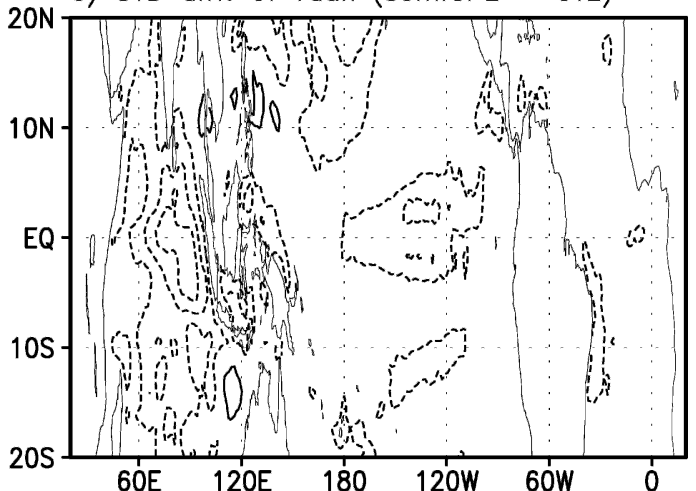

d) STD diff. of temp. at $4 \mathrm{~S}-4 \mathrm{~N}$

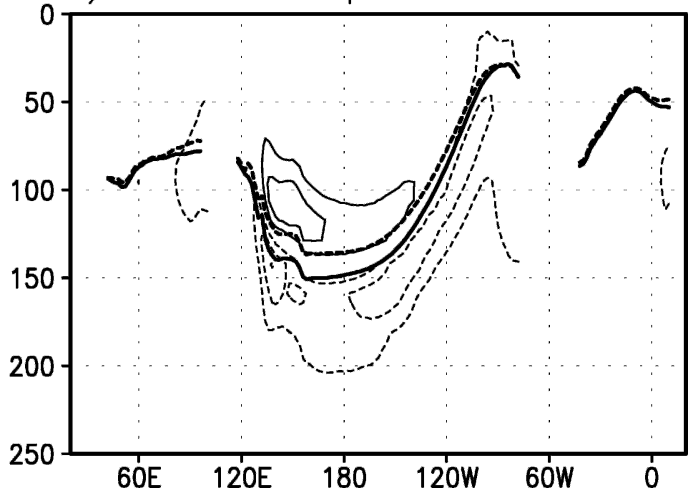

FIG. 8. Same as in Fig. 6, but for differences of standard deviation (STDs) of the zonal wind stress (contour: 0.01 dyne $\mathrm{cm}^{-2}$ ) and of upper-250-m ocean temperature (contour: $0.2^{\circ} \mathrm{C}$ ) along the equator $\left(4^{\circ} \mathrm{S}-4^{\circ} \mathrm{N}\right)$. Zero contours have been removed for clarity. (b) Thick solid (dashed) line denotes the depth where the strongest vertical temperature gradient occurs in the CTL (FCPL) run. (d) Similarly, the thick solid (dashed) line denotes that of the CTL (semi-CPL) run.

stronger surface easterly wind in the eastern Pacific because of the weakened vertical viscosity and enhanced instability in the atmospheric planetary boundary layer (PBL) over the warmer SST there (e.g., Wallace et al. 1989). On the contrary, more surface westerlies (i.e., weaker mean easterly trade winds) appear throughout the equatorial Pacific in the FCPL run (Fig. 10c). In addition to the large westerly difference in the western Pacific forced by the much warmer SST there, another maximum westerly difference appears east of about $120^{\circ} \mathrm{W}$. This corresponds to the slightly warmer SST near the eastern boundary of Pacific (see Fig. 3a). Therefore, the weakened surface easterly wind itself in the FCPL run gives rise to much more reduction of the easterly wind stress in the equatorial Pacific than in the semi-CPL run. In the free atmosphere, however, the wind differences in the FCPL run also follow the Matsuno-Gill pattern (Fig. 10d). The pattern is similar to what is produced in the semi-CPL run. The larger amplitudes correspond to the stronger cumulus heating over the larger SST warming in the western equatorial
Pacific. The results shown in Figs. 10c and 10d suggest that a shallow anomalous zonal cell within the PBL exists in the eastern equatorial Pacific.

Using a simple PBL model, Lindzen and Nigam (1987) found that a large part of the low-level winds in the tropical Pacific are directly driven by horizontal pressure gradients as a result of the horizontal SST gradients. Consistently, the lower surface pressure in the equatorial Pacific is closely related with warmer SST produced in the semi-CPL and FCPL runs (Fig. 11a). Forced by the zonal pressure gradients, westerly (easterly) anomalies relative to the zonal basinwide mean generally appear west (east) of the pressure trough (Fig. 11b). As shown before, the zonally averaged surface easterly wind of the FCPL run (thick solid line in Fig. 11b) is about $0.55 \mathrm{~m} \mathrm{~s}^{-1}$ weaker than that of the semi-CPL run (thick dashed line in Fig. 11b). Moreover, local westerly anomalies above the zonal basinwide mean appear east of $120^{\circ} \mathrm{W}$ (thin solid line in Fig. 11b). This is caused by the slightly warmer SST near the eastern boundary (thick solid line in Fig. 11a). The lat- 
a) CTL Regres. Z500 (DJF) on Nino3 SSTA

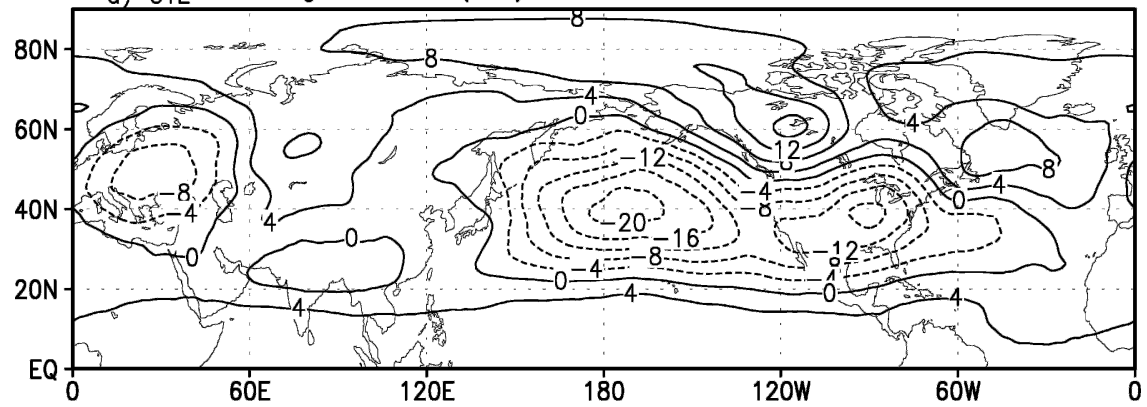

b) semiCPL

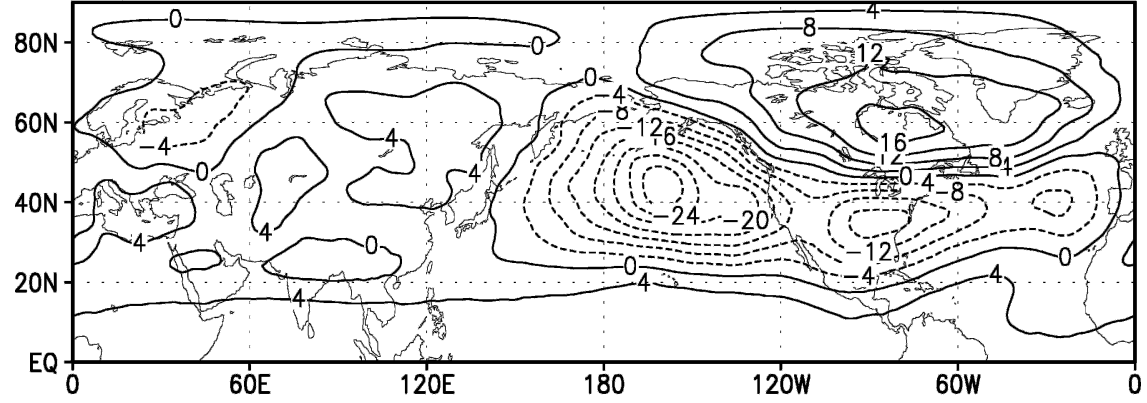

c) FCPL

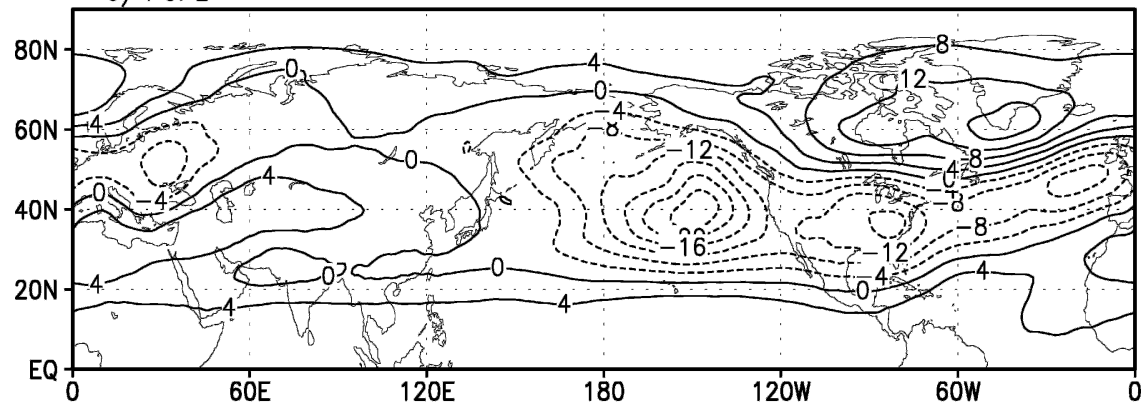

d) Obs. (NCEP)

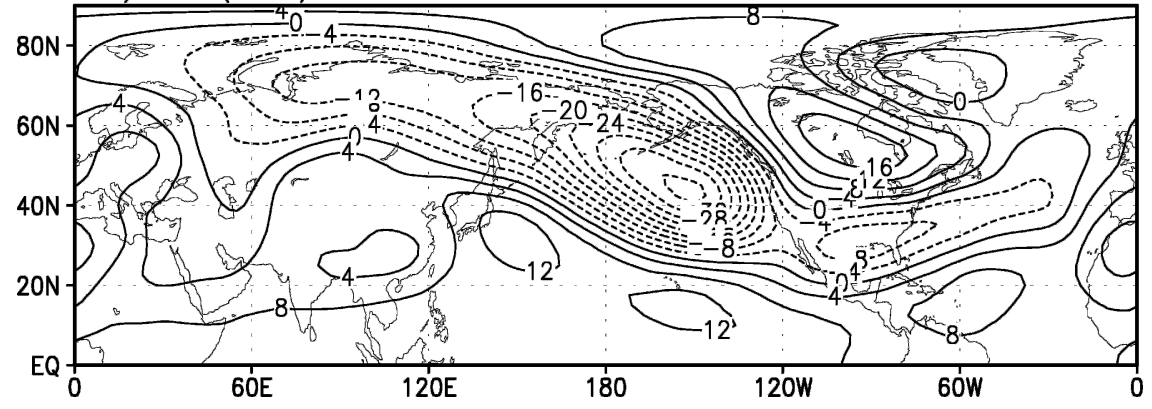

FIG. 9. Same as in Fig. 7, but for the regressed 500-hPa geopotential height anomaly in the Northern Hemisphere during winter (from Dec to Feb).

ter also tends to increase the shallow convection activities in the eastern Pacific, especially during the spring (see Fig. 4a). The anomalous convection reaches the top of the PBL (solid line in Fig. 11c). We note that the strong trade inversion in the eastern Pacific may suppress deep convection there. Thus, the stronger shallow convection over the slightly warmer SST near the east- ern boundary tends to induce more westerlies and a shallow anomalous zonal cell within the atmospheric PBL in the eastern equatorial Pacific.

Another important difference between the FCPL and semi-CPL runs is that the ocean surface current momentum has been directly passed to the atmosphere in the former experiment. The external momentum 

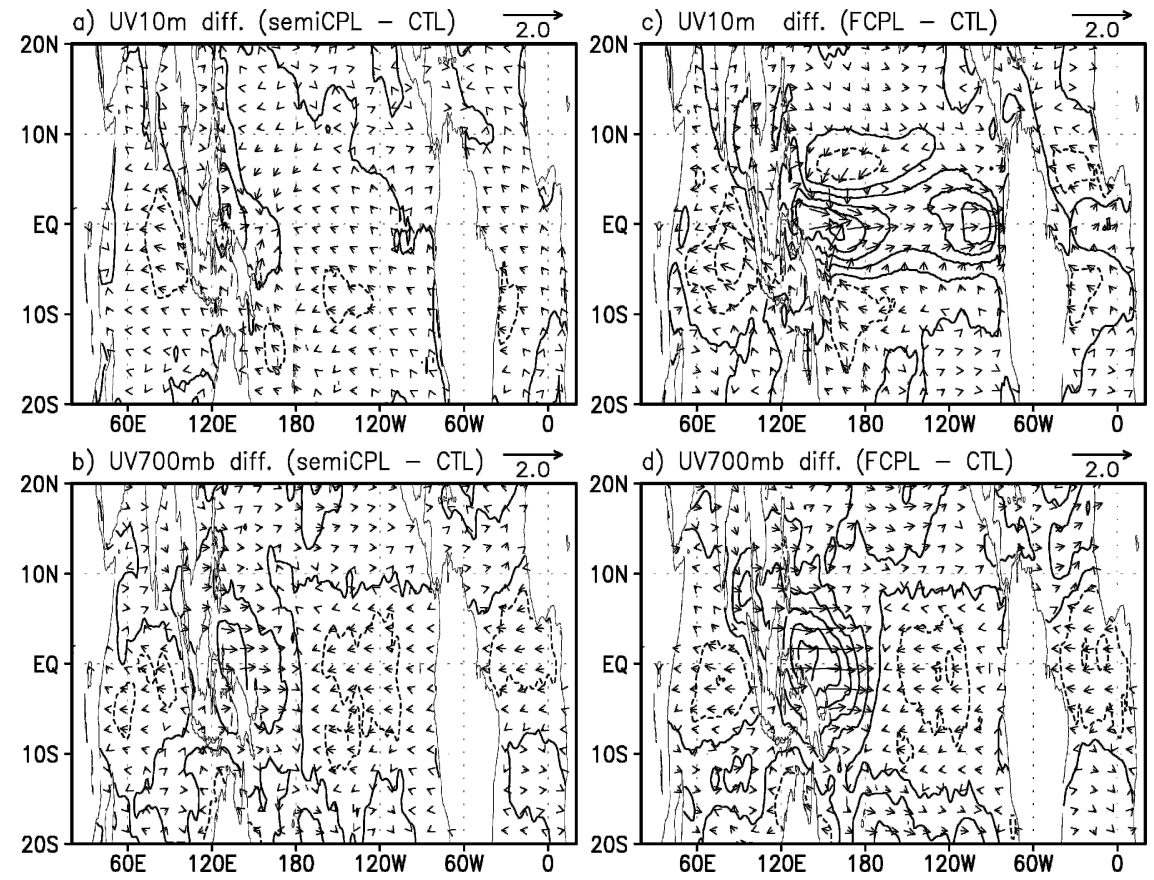

FIG. 10. Same as in Figs. 5d and 5b, but for differences of winds at a 10-m height and at 700-hPa pressure level (contour: $0.2 \mathrm{~m} \mathrm{~s}^{-1}$ ), respectively.

source affects the global angular momentum budget of the atmosphere. Figure 12 shows differences among the FCPL, semi-CPL, and CTL runs of the zonally averaged zonal wind stress over the global oceans at each latitude. We note that adding the wind stress differences over land surfaces gives similar results. One can see that the westerly wind stress over the Antarctic Circumpolar Current (ACC) region has been greatly reduced compared to other regions (solid line in Fig. 12). This, together with another small reduction in the northern midlatitudes, requires less easterly wind stress in the Tropics simply because the angular momentum gained by the atmosphere in the Tropics must be balanced by the loss in the extratropics (see, e.g., chapter 10 of Holton 1992). This tends to induce an additional reduction of the easterly trade winds in the tropical oceans. Indeed, this effect seems to overwhelm the influence of the zonal surface pressure gradient in the equatorial Atlantic (see Figs. 10c and 3a). We note that, however, easterly differences appear in the equatorial Indian Ocean. This is probably because of the remote influence from the Pacific. The reductions of both the westerly wind stress in the extratropics and the easterly wind stress in the Tropics in the FCPL run are larger than those of the semi-CPL run because of the pure contributions of the surface current (dashed line in Fig. 12). This indicates the influence of the atmospheric meridional general circulation adjustment. However, it is unclear at present how the new global angular momentum budget gets balanced through meridional eddy momentum flux changes, and what is the quantitative effect of the general circulation adjustment on weakening the mean easterly trade winds in the equatorial Pacific. This requires further study.

\section{b. How do the different coupling systems reach different steady states?}

To investigate the relative importance of each physical process to the SST differences among the FCPL, semi-CPL, and CTL runs, we have rerun the three experiments starting from the same initial conditions for the first $20 \mathrm{yr}$. Monthly mean tendency terms of the oceanic mixed layer heat budgets that have been computed at each time step have been stored. The mixed layer depth is defined as the depth at which the water is $0.01 \mathrm{~kg} \mathrm{~m}^{-3}$ denser than the surface water. The mixed layer heat budget is governed by horizontal and vertical advection, heat flux forcing, vertical entrainment computed from the turbulent kinetic energy scheme and the mixed layer depth fluctuations, isopycnal diffusion, and advection by eddy-induced velocities originating in the Gent and McWilliams (1990) scheme. The last term is found to be negligible in the Tropics. For the mixed layer heat budget installed in the OPA OGCM, readers are referred to Vialard and Delecluse (1998).

Differences in the 20-yr mean mixed layer tempera- 

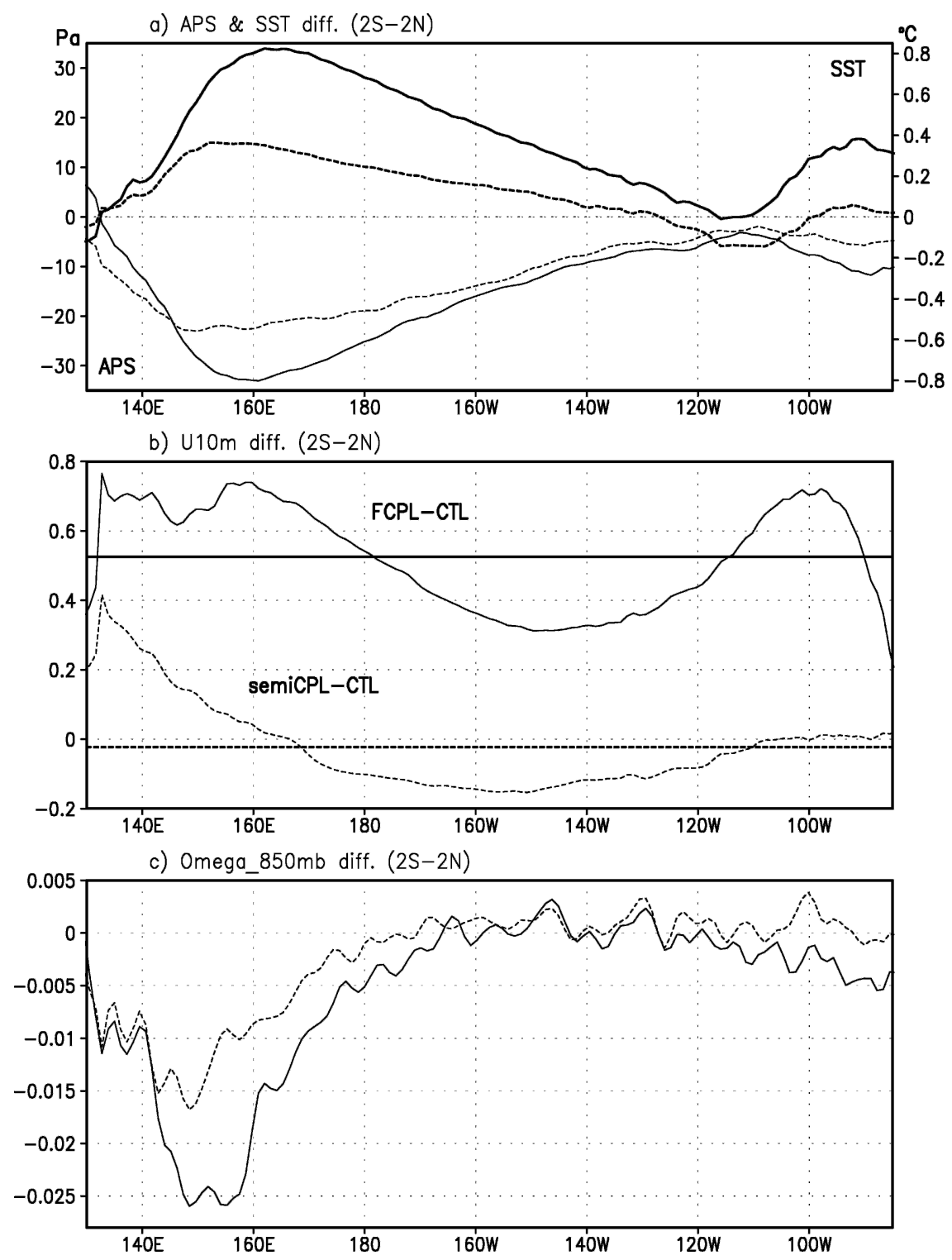

FIG. 11. (a) Differences of the last 100-yr mean surface air pressure (APS; thin lines) and SST (thick lines) between the FCPL and CTL (solid lines) runs, and between the semi-CPL and CTL (dashed lines) runs along the equatorial Pacific $\left(2^{\circ} \mathrm{S}-2^{\circ} \mathrm{N}\right)$. (b) Same as in (a), but for differences of equatorial zonal surface wind. Thick lines denote the zonally averaged values between $130^{\circ} \mathrm{E}$ and $85^{\circ} \mathrm{W}$. (c) Same as in (b), but for differences of vertical velocity (unit: $\mathrm{Pa}$ $\mathrm{s}^{-1}$ ) at $850-\mathrm{hPa}$ level.

ture ( $T_{m}$, equivalent to SST) among the FCPL, semiCPL, and CTL runs are similar to the steady-state differences of SST (not shown, see Fig. 3). To understand how the different coupling physics help to reach different steady states in the tropical Pacific, we integrate each tendency term of the mixed layer heat budget to get its monthly $T_{m}$ for the first $20 \mathrm{yr}$. Main contributions to the differences in the 20 -yr mean $T_{m}$ are plotted in Fig. 13. We note that the physical processes represented by these tendency terms are systematically affected by the different coupling physics. Therefore, the results should also explain the differences in the final steady states. The horizontal advection term of the FCPL run, compared to the CTL run, shows a positive contribution to the warmer SST in the western equatorial Pacific owing to the much-reduced surface westward current there (Fig. 13a). In the eastern part, however, this term tends to generate colder SST. The surface meridional current in the eastern Pacific advects colder water from south of the equator, as can be expected from the 


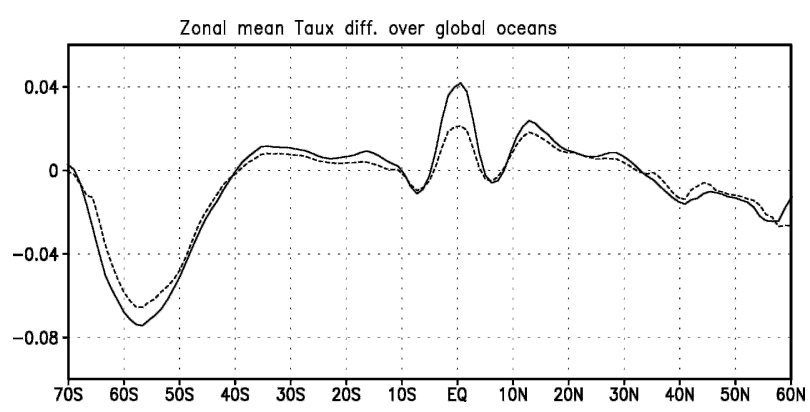

FIG. 12. Same as in Fig. 11a, but for differences of the zonal wind stress (unit: dyne $\mathrm{cm}^{-2}$ ) averaged over global oceans at each latitude from $70^{\circ} \mathrm{S}$ to $60^{\circ} \mathrm{N}$.

enhanced meridional SST gradient east of $120^{\circ} \mathrm{W}$ (see Fig. 3a). The total effect of the horizontal advection term is, therefore, to produce a more realistic warmpool/cold-tongue structure in the equatorial Pacific. The vertical entrainment term makes a large contribution to generating warmer SST basinwide. It has two local maxima in the western and eastern Pacific, respectively (Fig. 13b). Throughout the equatorial Pacific, the vertical diffusion that is caused by wind turbulence is weakened as a result of the reduced easterly wind stress (Blanke and Delecluse 1993). In the western Pacific, entrainment of subsurface cold water into the mixed layer is effectively blocked by the presence of a thicker barrier layer that is associated with the enhanced convective precipitation there (see Fig. 6). In contrast, the isopycnal diffusion term plays a basinwide cooling role (Fig. 13c). It largely balances the warming tendency of the entrainment term. In the western Pacific, the warmer SST is further damped by the surface heat flux forcing (Fig. 13d). Differences in the mixed layer heat budget between the semi-CPL and CTL run are similar, but with smaller values (Figs. 13e-h). Associated with persistent weaker surface easterlies east of about $120^{\circ} \mathrm{W}$, the vertical entrainment is reduced much more in the FCPL run than in the semi-CPL run (Figs. 13b and 13f). This may explain the small warmer SST difference near the eastern boundary (see Fig. 3a).

\section{Summary and discussions}

Most current ocean-atmosphere coupled GCMs are unable to simulate the correct warm-pool/cold-tongue structure in the equatorial Pacific. The model cold tongue is found to extend too far west. This common bias has not yet been resolved effectively, because the tropical air-sea interactions that largely determine the tropical climatology may aggravate the uncoupled GCM errors. This bias also exists in the relatively highresolution SINTEX-F CGCM despite its good perfor- mance in simulating ENSO variability. Any error of the surface wind stress, which is a key measure of the airsea coupling associated with both the Walker and Hadley cells, could lead to a significant bias in the tropical Pacific climatology. Nevertheless, the potential effect of the strong ocean surface current on wind stress in the equatorial Pacific has been ignored in most existing CGCMs.

Utilizing the SINTEX-F CGCM, we have implemented several sensitivity experiments. In the FCPL run, we pass the ocean surface current momentum directly to the atmosphere. In the semi-CPL run, only the wind stress is calculated from the relative velocity between the surface wind and ocean current. Compared to the CTL run in which the contribution of the ocean surface current is neglected, the reduced easterly wind stress in the semi-CPL and FCPL runs induces weaker surface zonal advection of cold SST from the east and weaker vertical entrainment in the western equatorial Pacific. This gives rise to a more realistic warm-pool structure. SST near the eastern boundary also increases, especially during the spring, owing to the reduced vertical entrainment there. The warming trend in the eastern Pacific, however, is largely suppressed by the isopycnal diffusion and meridional advection of colder SST from south of the equator that is associated with enhanced coastal upwelling near Peru. Westward extension of the colder water by oceanic advection tends to reduce the SST warming in the central equatorial Pacific. Therefore, the warm-pool/cold-tongue structure along the equatorial Pacific is simulated better in the semi-CPL and FCPL runs. Consequently, the dry bias over the western Pacific warm-pool region is much reduced. Furthermore, the ENSO signal in the western equatorial Pacific and its global teleconnections, especially in the Northern Hemisphere, are simulated more realistically. The warmer SST difference of the FCPL run in the western Pacific is double that of the semi-CPL run. This is because the surface easterly wind in the FCPL run is weakened, reducing the easterly wind stress further in the equatorial Pacific. The small, but significant, warmer SST near the eastern boundary in the FCPL run tends to strengthen the shallow convection and weaken the zonal Walker cell within the atmospheric PBL in the eastern equatorial Pacific. Finally, the external momentum source of the surface current, which is passed to the atmosphere, may affect its global angular momentum budget. This tends to further reduce the tropical easterly trade winds through meridional eddy momentum flux changes and the adjustment of the atmospheric meridional general circulation. Therefore, direct input of the ocean surface current momentum to the atmosphere is able to effi- 
a) Tm diff. due to hadv (FCPL - CTL)

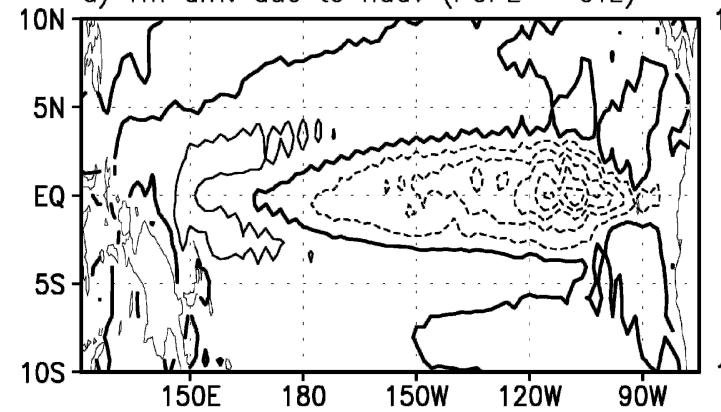

b) Vertical entrainment (FCPL - CTL)
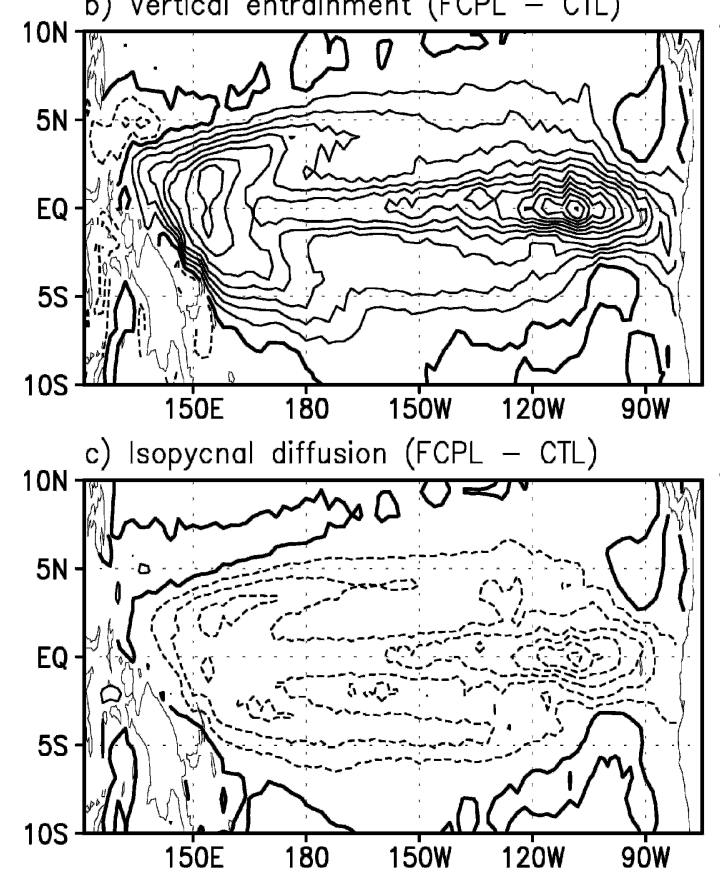

d) Heat flux forcing (FCPL $-C T L)$

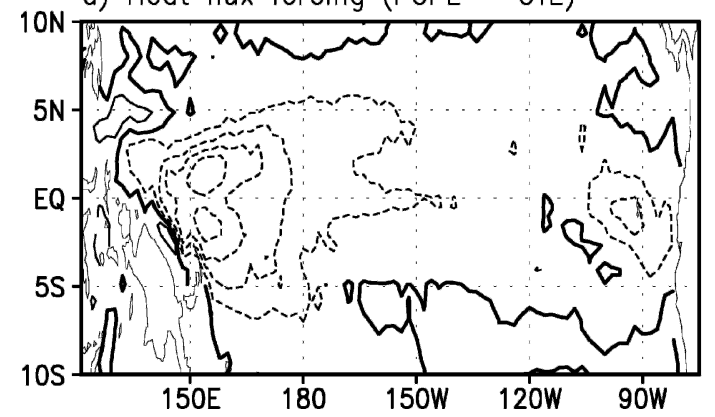

e) Tm diff. due to hadv (semiCPL - CTL)
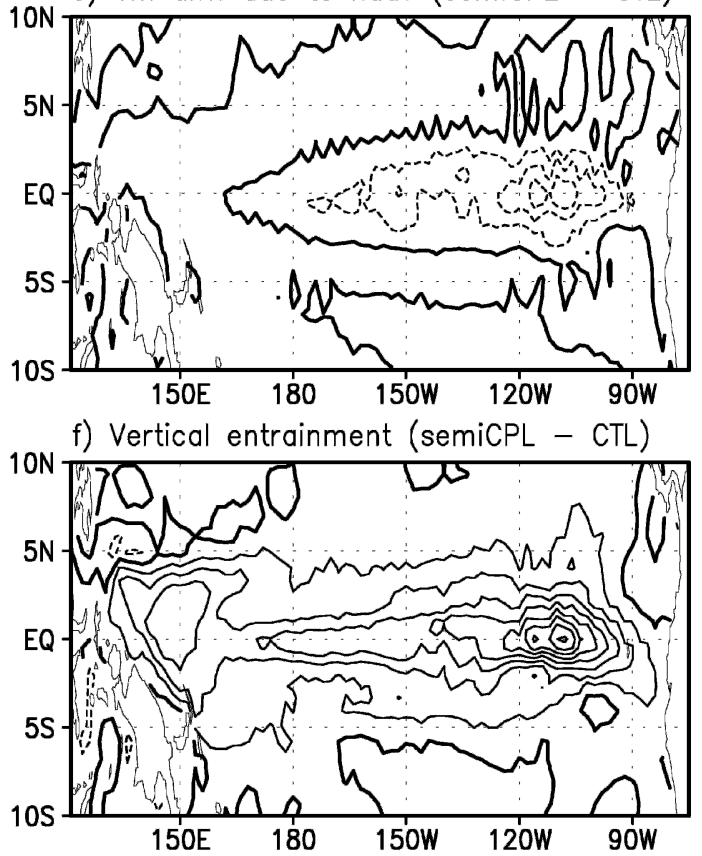

g) Isopycnal diffusion (semiCPL - CTL)

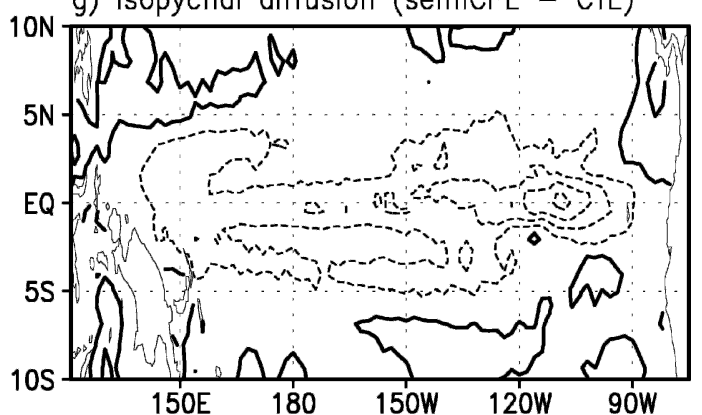

h) Heat flux forcing (semiCPL $-\mathrm{CTL})$

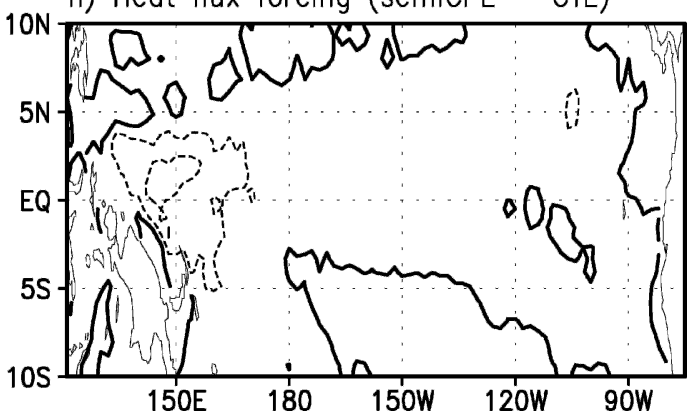

FIG. 13. Differences of the first 20-yr mean $T_{m}$ between the FCPL and CTL runs calculated from the contributions of the (a) horizontal advection, (b) vertical entrainment, (c) isopycnal diffusion, and (d) surface heat flux forcing, respectively. (e)-(h) Same as in (a)-(d), but for differences between the semi-CPL and CTL runs. Contour interval is $40^{\circ} \mathrm{C}$. Thick solid lines denote zero contours.

ciently improve the simulation of the warm-pool/coldtongue structure in the equatorial Pacific.

In contrast to the classical method of tuning individual uncoupled GCMs separately, we tried to tune the coupled GCM directly by improving the air-sea coupling physics in terms of its importance to both the climatology and ENSO variability in the tropical Pacific. Such an approach could be applied in a straightforward manner to any coupled GCM. For example, adopting the same approach as that of the FCPL run, 
the original strong cold SST bias $\left(\sim 2^{\circ} \mathrm{C}\right)$ of the MaxPlanck Institute for Meteorology CGCM has been largely reduced with about $1.5^{\circ} \mathrm{C}$ improvement in the equatorial Pacific (Jungclaus et al. 2005, manuscript submitted to J. Climate). We note, however, that taking the ocean surface current into account in the wind stress calculation does not improve the climatologies in the tropical Indian and Atlantic Oceans. The reasons for this, and methods that could reduce the biases there, need to be investigated further.

Acknowledgments. We thank Shang-Ping Xie, Yoshio Kurihara, Fei-Fei Jin, Eric Guilyardi, Johann Jungclaus, Boris Dewitte, and Brian Hoskins for helpful discussions; Tivon Jacobson for correcting English of the manuscript; and two anonymous reviewers for their valuable comments that helped improve the manuscript. Many European collaborators (e.g., INGV, the MPI-ECHAM group, the LODYC-OPA group, and the CERFACS-OASIS group) have been involved in development of the SINTEX-F CGCM. NCEP reanalysis data were provided by the NOAA-CIRES Climate Diagnostics Center library (information online at http://www.cdc.noaa.gov). The SINTEX-F model has been run on the Earth Simulator.

\section{REFERENCES}

AchutaRao, K., and K. R. Sperber, 2002: Simulation of the El Niño Southern Oscillation: Results from the Coupled Model Intercomparison Project. Climate Dyn., 19, 191-209.

Bjerknes, J., 1969: Atmospheric teleconnections from the equatorial Pacific. Mon. Wea. Rev., 97, 163-172.

Blanke, B., and P. Delecluse, 1993: Variability of the tropical Atlantic Ocean simulated by a general circulation model with two different mixed layer physics. J. Phys. Oceanogr., 23, $1363-1388$

Chang, P., and S. H. G. Philander, 1994: A coupled oceanatmosphere instability of relevance to the seasonal cycle. $J$. Atmos. Sci., 51, 3627-3648.

Charnock, M., 1955: Wind stress on a water surface. Quart. J. Roy. Meteor. Soc., 81, 639-640.

Chelton, D. B., M. G. Schlax, M. H. Freilich, and R. F. Milliff, 2004: Satellite measurements reveal persistent small-scale features in ocean winds. Science, 303, 978-983.

Davey, M., and Coauthors, 2002: STOIC: A study of coupled model climatology and variability in tropical ocean regions. Climate Dyn., 18, 403-420.

Delecluse, P., M. K. Davey, Y. Kitamura, S. G. H. Philander, M. Suarez, and L. Bengtsson, 1998: Coupled general circulation modeling of the tropical Pacific. J. Geophys. Res., 103, $14357-14373$.

Dijkstra, H. A., and J. D. Neelin, 1995: Coupled ocean-atmosphere interaction and the tropical climatology. Part II: Why the cold tongue is in the east. J. Climate, 8, 1343-1359.
Gent, P. R., and J. C. McWilliams, 1990: Isopycnal mixing in ocean circulation models. J. Phys. Oceanogr., 20, 150-155.

Gill, A. E., 1980: Some simple solutions for heat-induced tropical circulation. Quart. J. Roy. Meteor. Soc., 106, 447-462.

Gualdi, S., A. Navarra, E. Guilyardi, and P. Delecluse, 2003: Assessment of the tropical Indo-Pacific climate in the SINTEX CGCM. Ann. Geophys., 46, 1-26.

Guilyardi, E., P. Delecluse, S. Gualdi, and A. Navarra, 2003: Mechanisms for ENSO phase change in a coupled GCM. $J$. Climate, 16, 1141-1158.

— , and Coauthors, 2004: Representing El Niño in coupled ocean-atmosphere GCMs: The dominant role of the atmospheric component. J. Climate, 17, 4623-4629.

Holton, J. R., 1992: An Introduction to Dynamic Meteorology. Academic, $511 \mathrm{pp}$.

Horel, J. D., 1982: On the annual cycle of the tropical Pacific atmosphere and ocean. Mon. Wea. Rev., 110, 1863-1878.

Jin, F.-F., 1998: A simple model for the Pacific cold tongue and ENSO. J. Atmos. Sci., 55, 2458-2469.

Kelly, K. A., S. Dickinson, M. J. McPhaden, and G. C. Johnson, 2001: Ocean currents evident in satellite wind data. Geophys. Res. Lett., 28, 2469-2472.

Latif, M., A. Sterl, E. Maier-Reimer, and M. M. Junge, 1993: Climate variability in a coupled GCM. Part I: The tropical Pacific. J. Climate, 6, 5-21.

- and Coauthors, 2001: ENSIP: The El Niño Intercomparison Project. Climate Dyn., 18, 255-276.

Lindzen, R. S., and S. Nigam, 1987: On the role of sea surface temperature gradients in forcing low-level winds and convergence in the tropics. J. Atmos. Sci., 44, 2418-2436.

Liu, Z., and B. Huang, 1997: A coupled theory of tropical climatology: Warm pool, cold tongue, and Walker Circulation. $J$. Climate, 10, 1662-1679.

Louis, J. F., 1979: A parametric model of vertical eddy fluxes in the atmosphere. Bound.-Layer Meteor., 17, 187-202.

Luo, J.-J., S. Masson, S. Behera, P. Delecluse, S. Gualdi, A. Navarra, and T. Yamagata, 2003: South Pacific origin of the decadal ENSO-like variation as simulated by a coupled GCM. Geophys. Res. Lett., 30, 2250, doi:10.1029/2003GL018649.

,,--- S. Shingu, and T. Yamagata, 2005: Seasonal climate predictability of a coupled OAGCM using a different approach for ensemble forecasts. J. Climate, in press.

Ma, C.-C., C. R. Mechoso, A. W. Robertson, and A. Arakawa 1996: Peruvian stratus clouds and the tropical Pacific circulation: A coupled ocean-atmosphere GCM study. J. Climate, 9, 1635-1645.

Madec, G., P. Delecluse, M. Imbard, and C. Levy, 1998: OPA 8.1 ocean general circulation model reference manual. LODYC/ IPSL Tech. Rep. Note 11, 91 pp.

Matsuno, T., 1966: Quasi-geostrophic motions in the equatorial area. J. Meteor. Soc. Japan, 44, 25-43.

Mechoso, C. R., and Coauthors, 1995: The seasonal cycle over the tropical Pacific in coupled ocean-atmosphere general circulation models. Mon. Wea. Rev., 123, 2825-2838.

Meehl, G. A., P. R. Gent, J. M. Arblaster, B. L. Otto-Bliesner, E. C. Brady, and A. Craig, 2001: Factors that affect the amplitude of El Nino in global coupled climate models. Climate Dyn., 17, 515-526.

Mitchell, T. P., and J. M. Wallace, 1992: The annual cycle in equa- 
torial convection and sea surface temperature. J. Climate, $\mathbf{5}$, 1140-1156.

Morcrette, J.-J., L. Smith, and Y. Fouquart, 1986: Pressure and temperature dependence of the absorption in longwave radiation parameterizations. Beitr. Phys. Atmos., 59, 455-469.

Neelin, J. D., and Coauthors, 1992: Tropical air-sea interaction in general circulation models. Climate Dyn., 7, 73-104.

Pacanowski, R., 1987: Effect of equatorial currents on surface stress. J. Phys. Oceanogr., 17, 833-838.

Philander, S. G. H., D. Gu, D. Halpern, G. Lambert, N.-C. Lau, T. Li, and R. C. Pacanowski, 1996: Why the ITCZ is mostly north of the equator. J. Climate, 9, 2958-2972.

Picaut, J., M. Ioualalen, C. Menkes, T. Delcroix, and M. J. McPhaden, 1996: Mechanism of the zonal displacements of the Pacific warm pool: Implications for ENSO. Science, 274, 1486-1489.

Rayner, N. A., D. E. Parker, E. B. Horton, C. K. Folland, L. V. Alexander, D. P. Rowell, E. C. Kent, and A. Kaplan, 2003: Global analyses of sea surface temperature, sea ice, and night marine air temperature since the late nineteenth century. $J$. Geophys. Res., 108, 4407, doi:10.1029/2002JD002670.

Roeckner, E., and Coauthors, 1996: The atmospheric general circulation model ECHAM-4: Model description and simulation of present-day climate. Max-Planck-Institut für Meteorologie Rep. 218, 90 pp.

Roullet, G., and G. Madec, 2000: Salt conservation, free surface and varying volume: A new formulation for ocean GCMs. $J$. Geophys. Res., 105, 23 927-23 942.

Schneider, E. K., 2002: Understanding differences between the equatorial Pacific as simulated by two coupled GCMs. J. Climate, 15, 449-469.

Tiedtke, M., 1989: A comprehensive mass flux scheme for cumulus parameterization in large-scale models. Mon. Wea. Rev., 117, $1779-1800$

Tozuka, T., J.-J. Luo, S. Masson, S. K. Behera, and T. Yamagata, 2005: Annual ENSO simulated in a coupled oceanatmosphere model. Dyn. Atmos. Oceans, 39, 41-60.

Valcke, S., L. Terray, and A. Piacentini, 2000: The OASIS coupler user guide version 2.4. CERFACE Tech. Rep. TR/CGMC/ 00-10, $85 \mathrm{pp}$.

Vialard, J., and P. Delecluse, 1998: An OGCM study for the TOGA decade. Part I: Role of salinity in the physics of the western Pacific fresh pool. J. Phys. Oceanogr., 28, 1071-1088.

Wallace, J. M., T. P. Mitchell, and C. Deser, 1989: The influence of sea-surface temperature on surface wind in the eastern equatorial Pacific: Seasonal and interannual variability. $J$. Climate, 2, 1492-1506.

Xie, P., and P. A. Arkin, 1996: Analyses of global monthly precipitation using gauge observations, satellite estimates, and numerical model predictions. J. Climate, 9, 840-858.

Xie, S.-P., and S. H. G. Philander, 1994: A coupled oceanatmosphere model of relevance to the ITCZ in the eastern Pacific. Tellus, 46A, 340-350. 